\title{
Induction of apoptosis and erythroid differentiation of human chronic myelogenous leukemia K562 cells by low concentrations of lidamycin
}

\author{
CHU ZHANG $^{1 *}$, LU-YING GUO ${ }^{2 *}$, DAN MU ${ }^{2}$, JIAN-HUA GONG ${ }^{3}$ and JING CHEN ${ }^{2}$ \\ ${ }^{1}$ School of Pharmacy, China Pharmaceutical University, Nanjing, Jiangsu 210009; ${ }^{2}$ College of Life Sciences, \\ North China University of Science and Technology, Tangshan, Hebei 063210; ${ }^{3}$ Institute of Medicinal Biotechnology, \\ Chinese Academy of Medical Sciences and Peking Union Medical College, Beijing 210009, P.R. China
}

Received April 25, 2018; Accepted October 30, 2018

DOI: 10.3892/or.2018.6849

\begin{abstract}
Apoptosis induction and differentiation of promyelocytic leukemic cells into mature cells are major strategies for the drug-based treatment of leukemia. Lidamycin (LDM) which is a member of the enediyne antibiotic family exhibits extreme cytotoxicity. In the present study, the induction of apoptosis and differentiation in human chronic myeloid leukemia K562 cells by low concentrations of lidamycin were investigated. K562 cells were treated with lidamycin at various concentrations for $48 \mathrm{~h}$, and accumulated in the metaphase as determined in previous experiments. Cell viability was determined using a Cell Counting Kit-8 (CCK-8) assay and the $\mathrm{IC}_{50}$ value of lidamycin was $0.1 \pm 3.2 \mathrm{nM}$. Induction of apoptosis was investigated morphologically by acridine orange/ethidium bromide ( $\mathrm{AO} / \mathrm{EtBr})$ staining. Growth inhibition and apoptosis induction were observed in cells treated with low concentrations of lidamycin. In addition, western blot analysis revealed that treatment of the K562 cells with lidamycin at low concentrations upregulated the expression of caspase- 8 and caspase- 3 . The induction of differentiation in human chronic myeloid leukemia K562 cells by lidamycin at low concentrations was also investigated. The nitroblue tetrazolium reduction ability of K562 cells was increased following treatment with lidamycin. Low concentrations of lidamycin
\end{abstract}

Correspondence to: Dr Jing Chen, College of Life Sciences, North China University of Science and Technology, 21 Bohai Road, Caofeidian Xincheng, Tangshan, Hebei 063210, P.R. China

E-mail: chjingchuchu@hotmail.com

Dr Jian-Hua Gong, Institute of Medicinal Biotechnology, Chinese Academy of Medical Sciences and Peking Union Medical College, 1 Tiantan Xili, Beijing 100050, P.R. China

E-mail: ann_gong@hotmail.com

*Contributed equally

Key words: lidamycin, chromic myeloid leukemia, apoptosis, differentiation triggered erythroid differentiation among K562 cells, indicated by morphological changes, increased hemoglobin content, and the expression of cell surface antigens such as CD71. Additionally the expression of GATA-binding factor 1 (GATA-1) protein in low concentration lidamycin-treated K562 cells was increased. The results of the present study suggest that a low-concentration lidamycin exerts effects on apoptosis and erythroid differentiation induction by increasing the expression of caspases and GATA-1 protein. Lidamycin may serve a positive role in relevant targeted chemotherapy and may represent a potential candidate for chronic myelogenous leukemia differentiation-inducing treatment.

\section{Introduction}

Chronic myelogenous leukemia (CML) is a lethal malignancy. The increased and unregulated growth of predominantly myeloid cells in the bone marrow is the main characteristic of CML. CML has a morbidity of 1-2 cases per 100,000 adults and is responsible for $\sim 15 \%$ of all newly diagnosed cases of leukemia in adults (1). The majority of patients with CML fail to respond effectively to the current regimen of drug therapy due to occurrence of drug resistance. Bone marrow or allogenic stem cell transplantations are recent and effective treatments for CML, but they have a high risk of morbidity and mortality (2). CML places considerable burden on patients and the majority of chemotherapeutic drugs have long-term side effects $(3,4)$. Therefore, it is important to continue research into novel therapeutic approaches for CML. With regard to the induction of apoptosis, it is generally believed that drugs cause the elimination of cancer cells. Apoptosis is a type of cell death used by multicellular organisms to prevent uncontrolled proliferation and to dispose of unwanted cells. Apoptosis is originally characterized by morphological changes, including membrane blebbing, DNA fragmentation, chromatin condensation, nuclear fragmentation, cell shrinkage and apoptotic body formation (5). Resistance to apoptosis is a reason for concern in developing effective chemotherapeutic agents in various types of cancer. In addition, differentiation-inducing therapy has been proven to be a promising strategy. To date, all-trans retinoic acid-based therapy of acute promyelocytic 
leukemia (APL) has been the best clinical application of differentiation therapy (6,7). However, the development of differentiation therapy for CML requires further investigation.

Lidamycin (LDM) is a macromolecular enediyne antitumor antibiotic (8). LDM has two parts: one is an enediyne chromophore (MW $843 \mathrm{Da}$ ) responsible for the extremely potent bioactivity of the antibiotic and the other is a noncovalently bound apoprotein (MW $10.5 \mathrm{kDa})(9,10)$. The two parts can be dissociated and reconstituted, and the biological activity of the rebuilt molecule is comparable to that of natural LDM (11,12). LDM can induce DNA damage (13). LDM is extremely cytotoxic and induces growth inhibition of transplantable tumors in mice (14-17). Furthermore, LDM exhibited a strong inhibitory effect on tumor metastasis and angiogenesis (18). At present, several clinical trials are in progress to assess the therapeutic efficacy of LDM in multiple cancer indications (19). To determine the function of LDM on CML, the present study investigated the effects of LDM on the K562 cell line as an experimental model for CML. The present study revealed that LDM was highly active in inhibiting cell growth and that a low concentration LDM could induce cell apoptosis by upregulating the expression of caspase- 8 and caspase- 3 . Furthermore, a low concentration of LDM increases the cell hemoglobin contents and induces erythroid differentiation of K562 cells by upregulating the expression of GATA-1.

\section{Materials and methods}

Cell culture. The human K562 cells were cultured in RPMI-1640 medium (Gibco; Thermo Fisher Scientific, Inc., Waltham, MA, USA) supplemented with $10 \%$ fetal bovine serum (FBS; Gibco; Thermo Fisher Scientific, Inc.), penicillin $(10 \mathrm{U} / \mathrm{ml})$ and streptomycin $(100 \mathrm{U} / \mathrm{ml})$ at $37^{\circ} \mathrm{C}$. The cells were accumulated in the metaphase in the following experiments.

Cell proliferation assay. A cell proliferation assay was performed using a Cell Counting Kit-8 (CCK-8; Beijing Zoman Biotechnology Co., Ltd., Beijing, China). In brief, the K562 cells were plated into 96-well plates at a density of 5,000 cells/well and incubated at $37^{\circ} \mathrm{C}$ overnight. Experimental cells were treated with various concentrations $\left(10^{-13}\right.$ to $\left.10^{-6} \mathrm{M}\right)$ of LDM for $48 \mathrm{~h}$ at $37^{\circ} \mathrm{C}$. Next, $10 \mu \mathrm{l}$ of CCK- 8 reagent was added into each well. Cells were incubated for $2 \mathrm{~h}$ at $37^{\circ} \mathrm{C}$ and optical density was measured at $450 \mathrm{~nm}$. The aforementioned experiments were performed in triplicate.

Morphological analysis of apoptotic cells. The K562 cells were seeded into 12 -well plates at $5 \times 10^{4}$ cells/well and exposed to LDM at concentrations of $0.01,0.1$ and $1 \mathrm{nM}$ for $48 \mathrm{~h}$. The morphology of apoptosis was evaluated by acridine orange/ethidium bromide (AO/EB) staining using a fluorescence microscope (magnification, x200) (BH2 system; Olympus Corp., Tokyo, Japan). Cells were washed with cold phosphate-buffered saline (PBS) and adjusted to a cell density of $5 \times 10^{5}$ cells/well. A total of $10 \mu 1$ cells was placed on a glass slide and mixed with AO/EB solution (1:1, v/v) to a final concentration of $100 \mu \mathrm{g} / \mathrm{ml}$. Each sample should be mixed just prior to microscopy. Acridine orange is a vital dye and will stain both live and dead cells. Ethidium bromide will

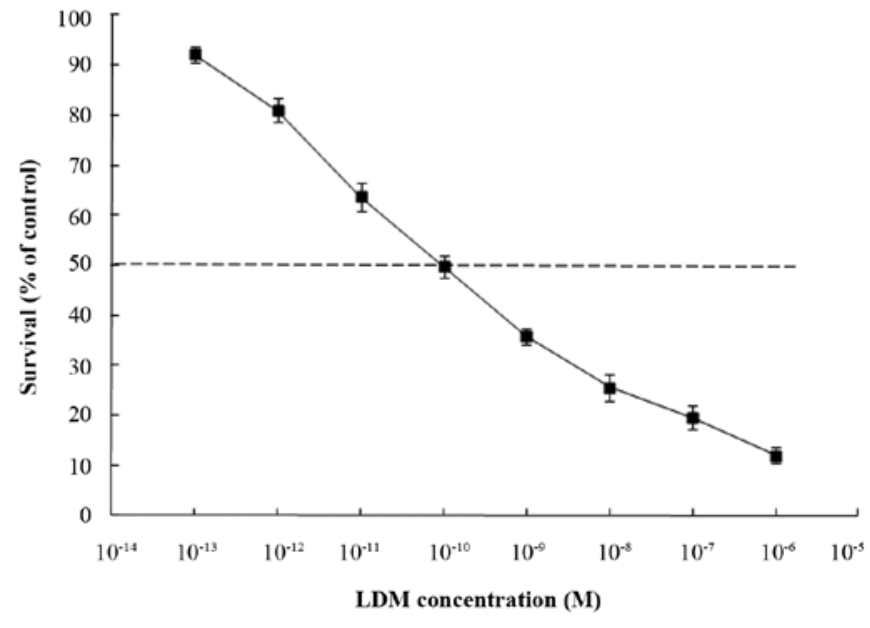

Figure 1. Effect of LDM on the proliferation of K562 cells. Cells were exposed to various concentrations of LDM for $48 \mathrm{~h}$. Cell viability was assessed by CCK-8 assay. Results were derived from three independent experiments. CCK-8 assay showed the potent inhibitory effects of LDM on K562 cell proliferation. The dashed line shows the $\mathrm{IC}_{50}$ value which was calculated by GraphPad Prism 7 software. LDM, lidamycin; CCK-8, Cell Counting Kit-8.

stain only cells that have lost membrane integrity. Live cells will appear uniformly green. Early apoptotic cells will stain green and contain bright green dots in the nuclei as a consequence of chromatin condensation and nuclear fragmentation. Late apoptotic cells will also incorporate ethidium bromide and therefore stain orange, but, in contrast to necrotic cells, the late apoptotic cells will show condensed and often fragmented nuclei. Necrotic cells stain orange, but have a nuclear morphology resembling that of viable cells, with no condensed chromatin (5).

In order to distinguish the apoptosis induction and look for the more effective drug dose, we used a lower concentration of LDM $(0.001 \mathrm{nM})$ and a higher concentration of LDM $(10 \mathrm{nM})$ in the following experiments.

Nitro blue tetrazolium (NBT) reduction experiment. The K562 cells were seeded into 12 -well plates at $5 \times 10^{4}$ cells/well and exposed to LDM for 48 or $72 \mathrm{~h}$. Next, cells were harvested and washed with PBS for 3 times. After $100 \mu 10.2 \%$ NBT solution containing TPA $(0.2 \mathrm{mg} / \mathrm{ml})$ was added, cells were incubated in the dark at $37^{\circ} \mathrm{C}$ for $30 \mathrm{~min}$ and $1 \mathrm{ml}$ cold PBS was added to terminate the reaction. The cells were then placed onto a glass slide and observed under a light microscope (magnification, x100). Three visual fields (each containing 200 cells) were randomly selected, and the percentage of blue punctate particle-positively stained cells was calculated using Mshot Image Analysis system (Micro-shot Technology Co., Ltd., Guangzhou, China).

Morphological analysis of K562 cells. The K562 cells were seeded into 12 -well plates at $5 \times 10^{4}$ cells/well and exposed to LDM for 48 or $72 \mathrm{~h}$. Morphological changes in the cells were evaluated by Wright-Giemsa staining using a fluorescence microscope (BH2 system; Olympus Corp.). Cells were washed with cold PBS and adjusted to a cell density of $5 \times 10^{5}$ cells/well. A total of $10 \mu \mathrm{l}$ cells was placed onto a glass slide, mixed with Giemsa and observed under a microscope. 


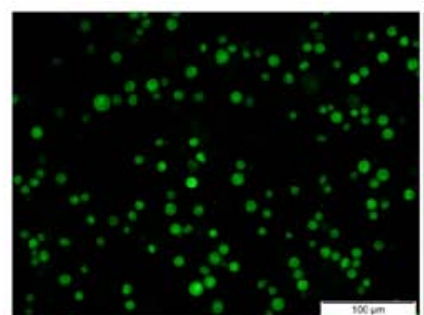

Control

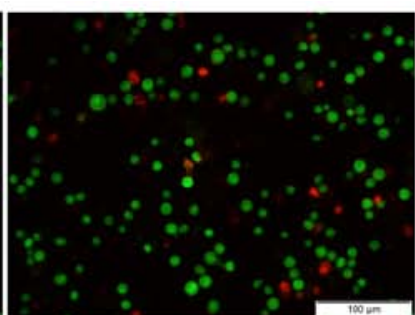

$0.01 \mathrm{nM}$

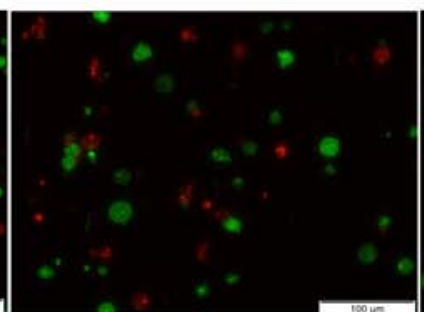

$0.1 \mathrm{nM}$

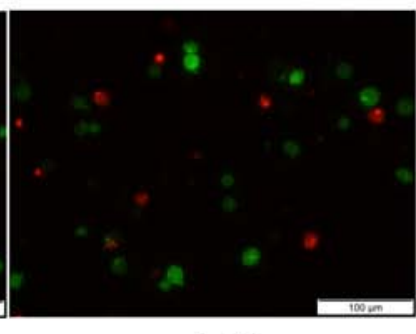

$1 \mathrm{nM}$

Figure 2. Morphological changes in the K562 cells treated with LDM. After treatment with LDM for 48 h, the cells were harvested and then stained with $\mathrm{AO} / \mathrm{EB}$. The live cells appeared green in color and the apoptotic cells were orange in color under a fluorescent microscope (magnification, x200). LDM, lidamycin; $\mathrm{AO} / \mathrm{EB}$, acridine orange/ethidium bromide.

Detection of hemoglobin contents. The K562 cells were seeded onto 6-well plates at $2 \mathrm{ml} /$ well and exposed to LDM for 48 or $72 \mathrm{~h}$. All the cells were harvested and lysed, and the concentration of hemoglobin was determined using a spectrophotometer. The aforementioned experiments were performed in triplicate.

CD71 expression assay. The expression of CD71 on the surface of K562 cells was assessed using a flow cytometer. The K562 cells were seeded into 6-well plates at $2 \mathrm{ml} /$ well and exposed to LDM for 48 or $72 \mathrm{~h}$. Cells were then harvested and the cell count was adjusted to $1 \times 10^{5}$ cells $/ \mathrm{ml}$. Following washing with PBS, cells were labeled with $20 \mu \mathrm{l}$ PE-conjugated anti-CD71 (BD Biosciences, San Jose, CA, USA) for $15 \mathrm{~min}$ in the dark at room temperature. Cells were washed twice with PBS and resuspended in $500 \mu \mathrm{l}$ PBS prior to measurement of CD71 expression. Fluorescence intensity was measured using FACSCanto II (BD Biosciences) in continuous mode (20).

Western blot analysis. The K562 cells were treated with LDM and harvested after 48 or $72 \mathrm{~h}$. Harvested cells were washed with PBS and then lysed using RIPA buffer [25 mM Tris (pH 7.8), 2 mM EDTA, 20\% glycerol, 0.1\% Nonidet P-40 (NP-40), $1 \mathrm{mM}$ dithiothreitol] and protease inhibitors. The protein concentrations of cell supernatants were determined with the BCA Protein Assay kit from Hyclone-Pierce. Proteins (30 $\mu \mathrm{g} / \mathrm{lane}$ ) were equally loaded to and separated by SDS-PAGE gel (15\%). After electrophoresis, proteins were transferred to polyvinylidene difluoride (PVDF) membrane (EMD Millipore, Bedford, MA, USA). Blots were blocked for $60 \mathrm{~min}$ at room temperature with $5 \%$ non-fat milk powder and $0.1 \%$ Tween-20 in PBS and exposed overnight at $4^{\circ} \mathrm{C}$ using primary antibodies against caspase-8 (sc-56071; Santa Cruz Biotechnology, Inc., Dallas, TX, USA), active caspase-8 (cat. no. 9748; Cell Signaling Technology, Inc., Danvers, MA, USA), caspase-3 (sc-56052; Santa Cruz Biotechnology, Inc.), active caspase-3 (cat. no. 9661; Cell Signaling Technology, Inc.), GATA-1 (sc-266) and $\beta$-actin (sc-130065) (both from Santa Cruz Biotechnology, Inc.). All the primary antibodies were diluted at 1:500. The membranes were incubated in horseradish peroxidase-labeled IgG secondary antibodies (1:1,000; sc-2380 and sc-2379; Santa Cruz Biotechnology, Inc.) at room temperature for $1 \mathrm{~h}$. The bands were visualized using enhanced chemiluminescence detection reagents (Santa Cruz Biotechnology, Inc.). Western blots were quantified via densitometry scanning using NIH Image software version 1.46 (National Institutes of Health, Bethesda, MD, USA).

Statistical analysis. Results are expressed as the mean \pm standard deviation (SD) of three independent experiments. Treatment effects were analyzed using the unpaired Student's t-test when comparing two variables, while inter-group and intra-group comparisons were conducted using one-way ANOVA test with post hoc contrasts by Student-NewmanKeuls test. A P-value of $\leq 0.05$ was considered to indicate a statistically significant difference.

\section{Results}

Effects of LDM on the proliferation of K562 cells. Inhibition of cell proliferation was measured using CCK-8 assays. K562 cells were treated with different concentrations of LDM for 48 h. CCK-8 assays revealed that cell viability was reduced following treatment with $\mathrm{LDM}$ and the $\mathrm{IC}_{50}$ value was $0.1 \pm 3.2 \mathrm{nM}$ which was calculated by GraphPad Prism 7 software (GraphPad Software, Inc., La Jolla, CA, USA (Fig. 1). Since LDM has extreme cytotoxicity to many cancer cells as well as normal cells, in order to reduce its toxicity, we explored the effects of low dose LDM. In our experiment, we chose 0.01 or $0.001 \mathrm{nM}$ as the low concentration.

Induction of apoptosis by LDM in K562 cells. AO/EB staining was used to detect the apoptosis of K562 cells. AO can inset the DNA of whole cells and show green fluorescence, while EB only penetrates the impaired cell membrane and shows orange red fluorescence. Fluorescence increases in an apoptotic cell. Under a fluorescence microscope, the nuclei of the control cells were large and round without condensation or fragmentation. By contrast, following exposure to LDM for $48 \mathrm{~h}$, the majority of cells presented with typical morphological changes of apoptosis, including chromatin condensation or shrunken nuclei (Fig. 2). In the group treated with higher concentrations of LDM, condensed nuclei were observed. The live cells appeared green in color with undamaged nuclei, while the early apoptotic cells exhibited condensed nuclei and were green in color with bright green dots in their nuclei, and the late apoptotic cells were orange in color. In addition, the number of cells also decreased in the 0.1 and $1 \mathrm{nM}$ LDM groups, respectively.

In addition, flow cytometry (FACS) analysis was carried out to determine the percentage of apoptosis. Unfortunately, 

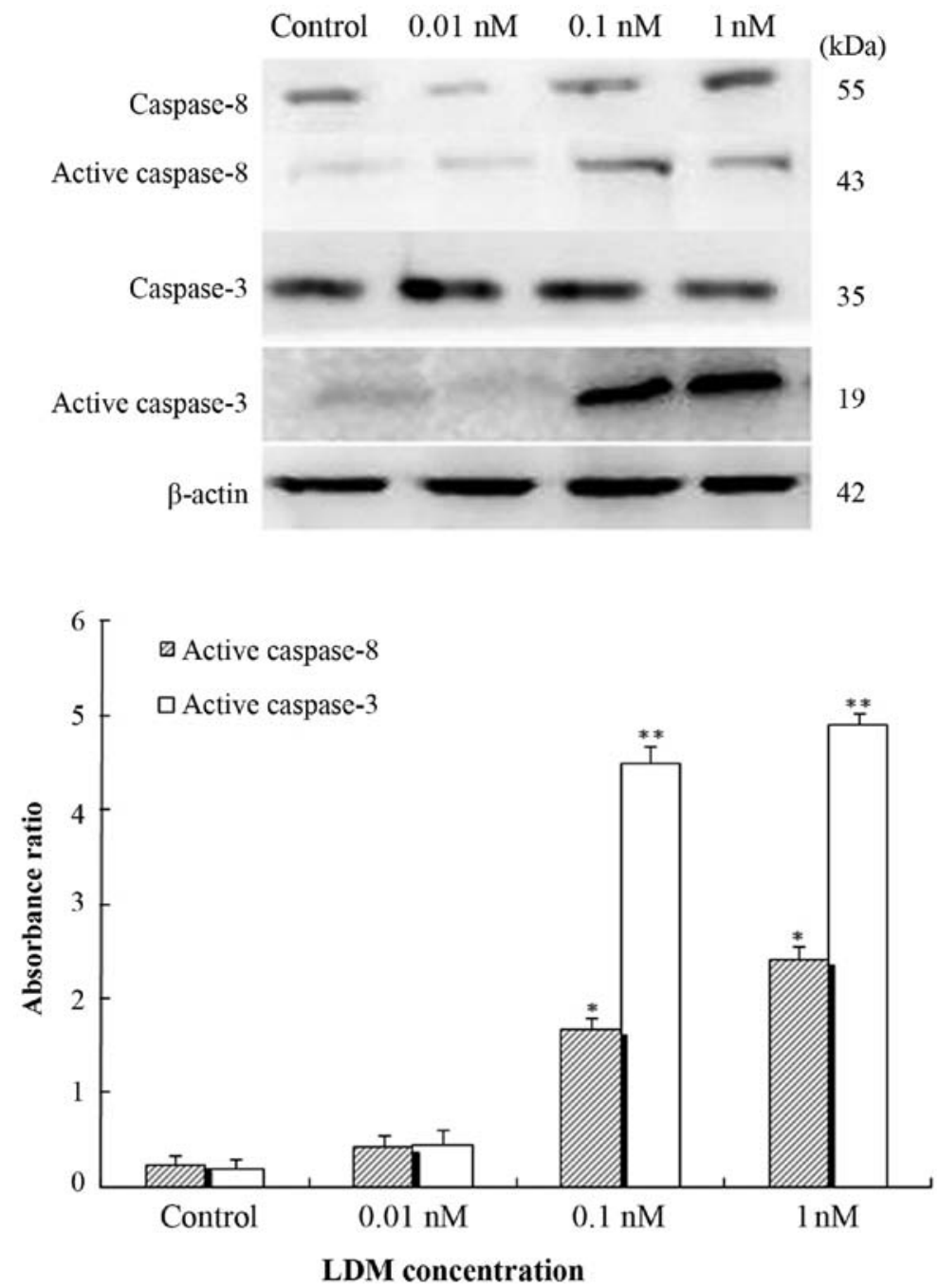

Figure 3. Effects of LDM on the expression of caspase-8, active caspase-8, caspase- 3 and active caspase- 3 proteins in K562 cells. The protein expression levels of caspase- 8 , active caspase- 8 , caspase-3, active caspase- 3 and $\beta$-actin in K562 cells treated with $0.01,0.1$ and $1 \mathrm{nM}$ of LDM were determined by western blot analysis. $\beta$-actin was used to normalize the individual expression levels. Data represent three independent experiments. $\left({ }^{*} \mathrm{P}<0.05,{ }^{* *} \mathrm{P}<0.01 \mathrm{vs}\right.$. control). LDM, lidamycin.

the results were unsatisfactory and this will be repeated in future studies.

Effects of LDM on the activation of apoptosis-related proteins in $K 562$ cells. Apoptosis is induced by the activation of a group of cysteine proteases called 'caspases', which cleave proteins during cell death. According to the function of caspases, they are grouped into two different subfamilies. One subfamily includes the initiation (caspase-8 and -9) and execution (caspase-3, -6 and -7) of the apoptotic program (initiator and executioner caspases). Caspase- 8 and caspase- 9 are caspases upstream of the apoptosis signal transduction process, while caspase- 3 is downstream, all of which are effector molecules of cell apoptosis. The activation of initiator caspase-8 will, in turn, activate caspase-3. Caspase- 3 is an executioner caspase in the last and irreversible phase of the apoptotic caspase-dependent pathway. The expression of caspase- 8 and caspase- 3 in K562 cells treated with $0.01,0.1$ and $1 \mathrm{nM}$ LDM was investigated by western blot analysis. As shown in Fig. 3, treatment with LDM for $48 \mathrm{~h}$ led to upregulation and activation of caspase- 8 and caspase-3 in K562 cells compared to controls.
Effect of LDM at low concentrations on the differentiation induction of $\mathrm{K} 562$ cells. To assess whether a low concentration of LDM could induce differentiation of K562 cells, the NBT reduction experiment was performed. Differentiated K562 cells can reduce NBT to dark blue diformazan particles, which can easily be observed under a light microscope. K562 cells were treated with $0.001,0.1$ and $10 \mathrm{nM}$ LDM for 48 or $72 \mathrm{~h}$. The NBT-positive percentages of the control group were $7.6 \pm 1.5$ and $10.3 \pm 1.7 \%$ at 48 and $72 \mathrm{~h}$, respectively, while the NBT-positive percentages of K562 cells were $45.7 \pm 4.2$, $52.5 \pm 2.7$ and $28.4 \pm 5.6 \%$ in the $0.001,0.1$ and $10 \mathrm{nM}$ groups, respectively, at $48 \mathrm{~h}$; and $59.4 \pm 3.1,73.1 \pm 1.9$ and $32.8 \pm 2.8 \%$ in the $0.001,0.1$ and $10 \mathrm{nM}$ groups, respectively, at $72 \mathrm{~h}$. To note, most cells died in the $10 \mathrm{nM}$ group, thus the NBT reduction rate was decreased (Fig. 4).

Effect of LDM at low concentrations on the induction of erythroid differentiation of K562 cells

Morphological changes of K562 cells. Wright-Giemsa staining revealed that a low concentration of LDM induced distinct morphological changes in K562 cells. In control groups, K562 
A

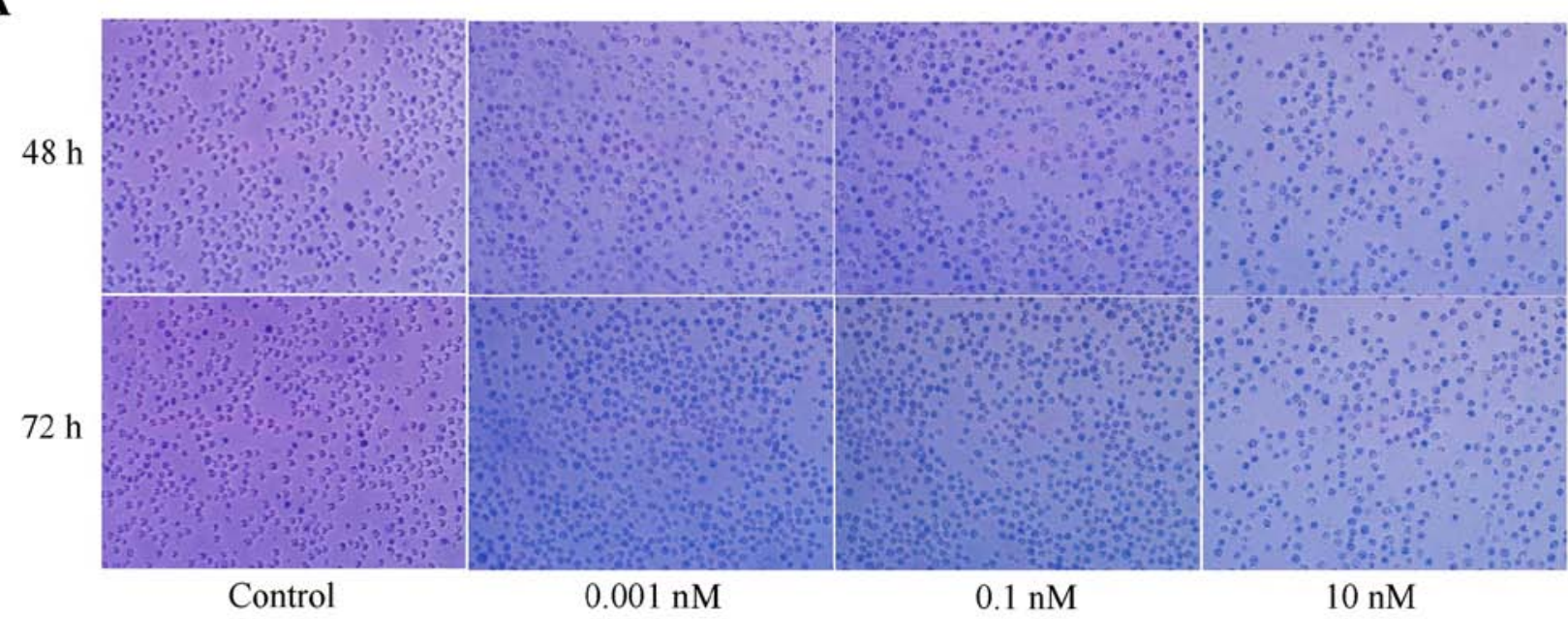

B

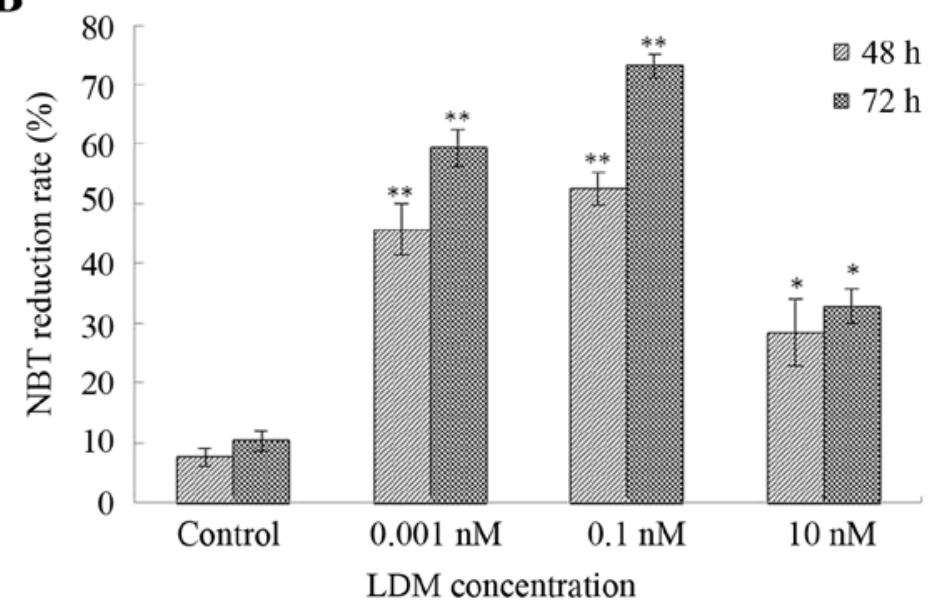

Figure 4. Effect of LDM on the NBT-reducing activity of K562 cells. NBT reduction assay for induction of differentiation in K562 cells by LDM. K562 cells were treated with $0.001,0.1$ and $10 \mathrm{nM}$ of LDM for 48 or $72 \mathrm{~h}$. (A) Cell images under light microscope (magnification, x100). The cells which present dark blue staining were positive cells. (B) The percentage of NBT-positive cells was calculated using an image analysis system. ${ }^{*} \mathrm{P}<0.05$, ${ }^{* *} \mathrm{P}<0.01 \mathrm{vs}$. control. LDM, lidamycin; NBT, nitroblue tetrazolium.

cells showed blue purple staining. While some cells showed pale pink in the 0.001 and $0.1 \mathrm{nM}$ LDM groups. This reflected some changes in cellular components. In addition, the cell volume also changed considerably. Most cells died in the $10 \mathrm{nM}$ LDM group. The cytoplasm of K562 cells following treatment with 0.1 and $0.001 \mathrm{nM}$ LDM for 48 or $72 \mathrm{~h}$ became more ample than that of the control group cells. These typical morphological changes showed a differentiation tendency for K562 cells (Fig. 5).

LDM increases the hemoglobin contents of K562 cells. The results of the hemoglobin content assay demonstrated that the level of hemoglobin in K562 cells was increased following treatment with LDM for 48 or $72 \mathrm{~h}$. In the 0.001 and $0.1 \mathrm{nM}$ LDM groups, the hemoglobin contents of K562 cells were markedly increased, compared with those in the control group. Additionally, most cells died in the $10 \mathrm{nM}$ group, thus there was a decrease in the hemoglobin content (Table I).

LDM increases the expression level of CD71 in K562 cells. The CD71 antigen is a classical erythroid differentiation marker expressed on the cell surface. Flow cytometric analysis
Table I. Influence of LDM on the hemoglobin content of K562 cells.

\begin{tabular}{lccc}
\hline \multirow{2}{*}{$\begin{array}{l}\text { Concentration of } \\
\text { LDM (nmol/l) }\end{array}$} & & \multicolumn{2}{c}{ Hemoglobin content $(\mu \mathrm{g} / \mathrm{l})$} \\
\cline { 3 - 4 } & $\mathrm{n}$ & $48 \mathrm{~h}$ & $72 \mathrm{~h}$ \\
\hline 0 & 3 & $0.273 \pm 0.024$ & $0.341 \pm 0.052$ \\
0.001 & 3 & $0.703 \pm 0.204^{\mathrm{a}}$ & $0.827 \pm 0.174^{\mathrm{a}}$ \\
0.1 & 3 & $0.833 \pm 0.314^{\mathrm{a}}$ & $1.157 \pm 0.162^{\mathrm{b}}$ \\
10 & 3 & $0.562 \pm 0.116^{\mathrm{a}}$ & $0.614 \pm 0.332^{\mathrm{a}}$
\end{tabular}

${ }^{\mathrm{a}} \mathrm{P}<0.05,{ }^{\mathrm{b}} \mathrm{P}<0.01$ vs. control $(0 \mathrm{nmol} / \mathrm{l})$ group. LDM, lidamycin.

demonstrated that LDM increased the expression level of CD71 in K562 cells. Compared with the control cells, the expression of CD71 was $10.1,16.7$ and $5.4 \%$ in the $0.001,0.1$ and $10 \mathrm{nM}$ groups, respectively, at $48 \mathrm{~h}$; and 26.3, 71.4 and $9.3 \%$ in the $0.001,0.1$ and $10 \mathrm{nM}$ groups, respectively, at $72 \mathrm{~h}$. The expression of CD71 in the 0.1 nM LDM-treated K562 


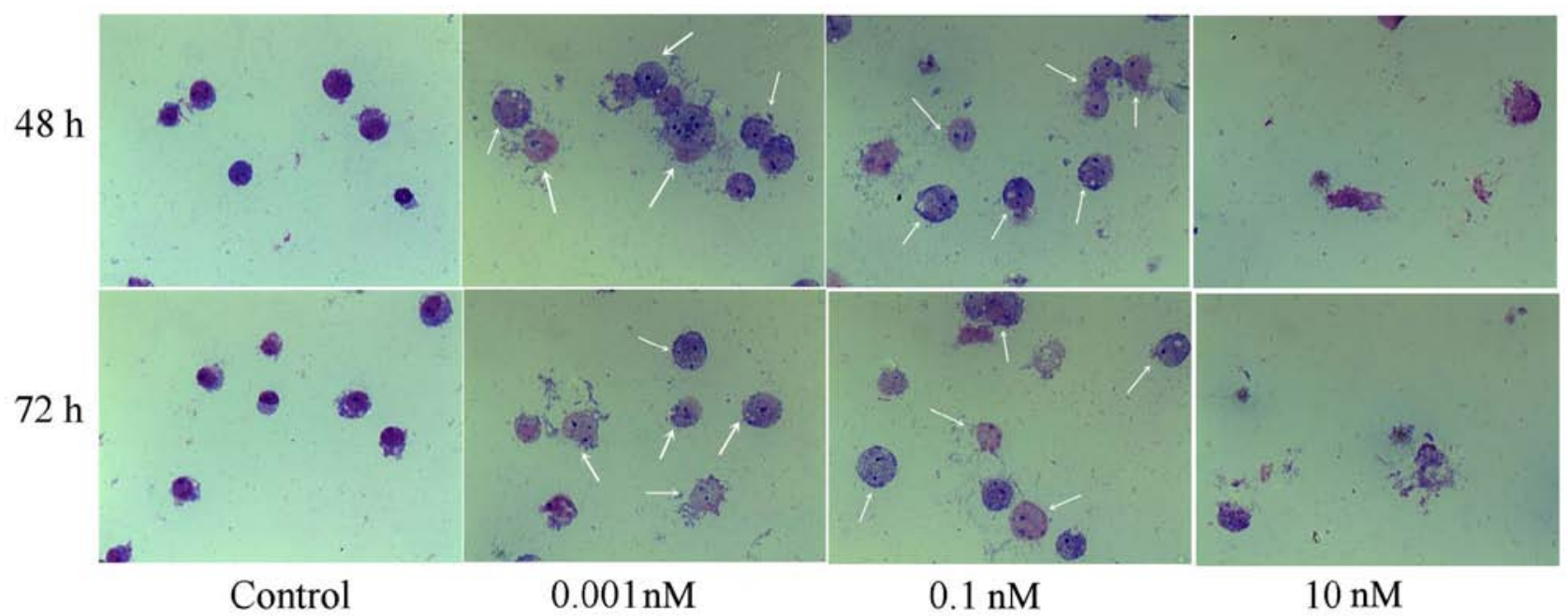

Figure 5. Morphological changes of K562 cells. K562 cells were treated with 0.001, 0.1 and $10 \mathrm{nM}$ of LDM for 48 or $72 \mathrm{~h}$, and the cell smears were stained with Wright-Giemsa. There were distinct morphological changes in K562 cells especially induced by 0.001 and $0.1 \mathrm{nM}$ of LDM, including an increase in the volume of the cells and irregular nuclei (magnification, x400). LDM, lidamycin.

A

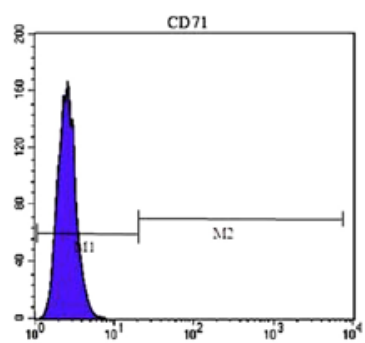

Control

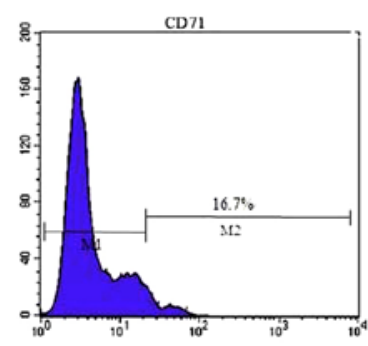

$0.1 \mathrm{nM}$

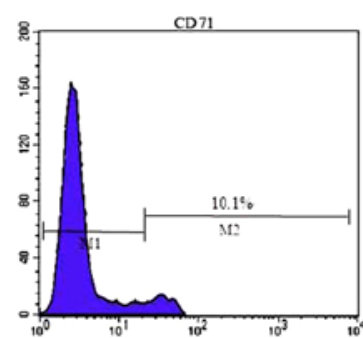

$0.001 \mathrm{nM}$

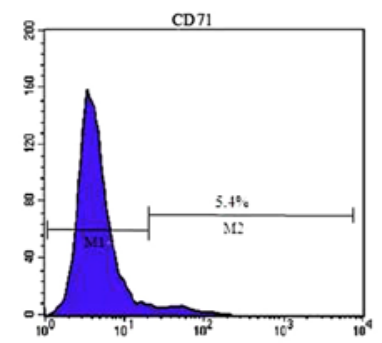

$10 \mathrm{nM}$

B

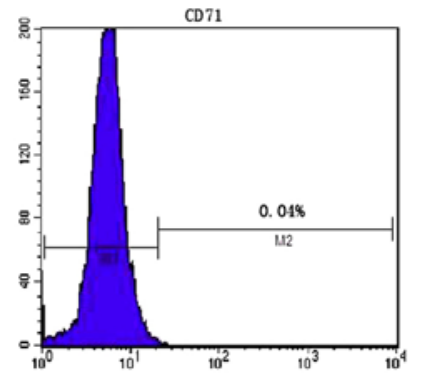

Control

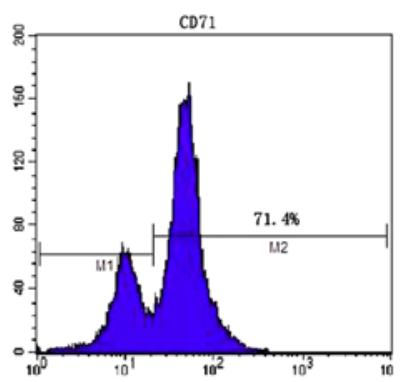

$0.1 \mathrm{nM}$

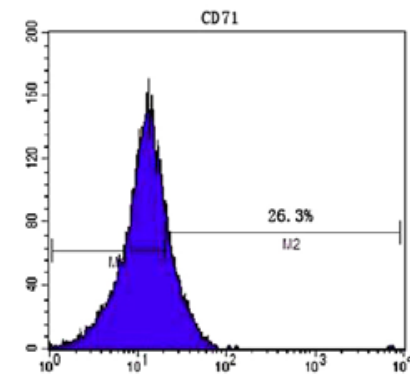

$0.001 \mathrm{nM}$

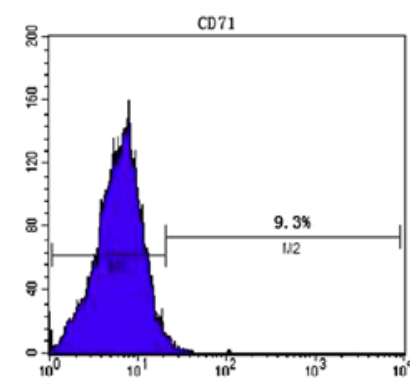

$10 \mathrm{nM}$

Figure 6. Effect of LDM on the CD71 expression of K562 cells. K562 cells were treated with $0.001,0.1$ and 10 nM of LDM for (A) 48 or (B) 72 h. Then cells were labeled with PE-conjugated anti-CD71 and the fluorescence intensity which presents the expression level of CD71 was measured by flow cytometry. LDM, lidamycin.

cells was significantly higher than that in the other group cells (Fig. 6). These results clearly demonstrated that low concentration LDM could induce the differentiation of K562 cells into erythroid lineage.

Activation of GATA-1 is associated with the erythroid-inducing differentiation mechanism in K562 cells by LDM at a low concentration. GATA-1 is a member of the GATA transcription factor family and is a key mediator of the development of specific types of blood cells from their precursor cells. Based on the erythroid-inducing differentiation effects of LDM on K562 cells and the significant role of GATA-1 in erythropoiesis, GATA-1 protein expression was detected by western blot analysis. The results demonstrated that following treatment with LDM for 48 and $72 \mathrm{~h}$, the GATA-1 protein expression in the K562 cells was increased compared with that in the control cells, while it was decreased in the $10 \mathrm{nM}$ group as most of the cells died (Fig. 7).

\section{Discussion}

Chronic myelogenous leukemia (CML) is a lethal hematological disorder originating from a small number of leukemia 
A

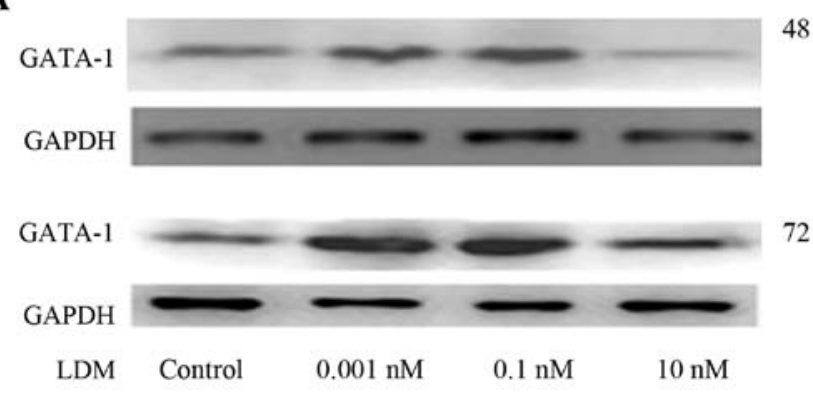

B

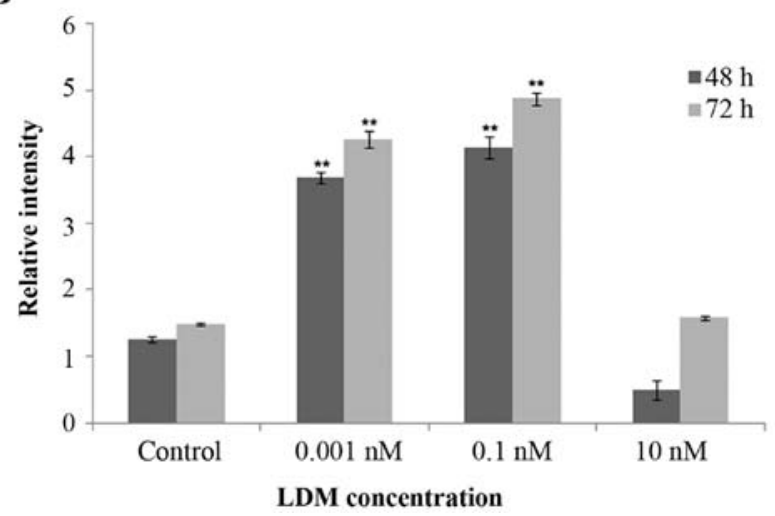

Figure 7. Effect of LDM on the GATA-1 expression of K562 cells. K562 cells were treated with $0.001,0.1$ and $10 \mathrm{nM}$ of LDM for 48 or $72 \mathrm{~h}$. (A) Western blot analysis for GATA-1 expression in the different treatment groups; GAPDH (sc-51631; Santa Cruz Biotechnology, Inc.) was used as an internal control. (B) Western blots were quantified via densitometry scanning using NIH Image software and plotted in histograms. Data were obtained from 3 independent experiments. ${ }^{*} \mathrm{P}<0.05,{ }^{* *} \mathrm{P}<0.01$ vs. control. LDM, lidamycin; GATA-1, GATA-binding factor 1.

stem cells. The properties of CML cells are as follows: uncontrolled growth, escape of apoptosis and differentiation disorder. Traditional chemotherapeutic agents inevitably act on healthy tissue. Therefore, induction of apoptosis or terminal differentiation is an attractive approach for the therapy of human leukemia. Lidamycin (LDM) is an antitumor antibiotic that is produced by a streptomyces globisporus C1027, which was isolated in China. LDM displays extreme cytotoxic and anti-angiogenic activity, as well as distinct growth inhibition against transplantable tumors in mice (16). The cytotoxicity of LDM is more powerful than that of mitomycin or doxorubicin (21). Currently, several phase II and phase III clinical trials are underway to evaluate the therapeutic efficacy of LDM in breast, non-small cell lung, colon cancer and lymphoma (19). The present study investigated the anticancer effect of LDM on the K562 cell line as an experimental model for CML. In the present study, it was observed that LDM decreased the viability of K562 cells in a dose-dependent manner and the $\mathrm{IC}_{50}$ value of lidamycin was $0.1 \pm 3.2 \mathrm{nM}$. Since the inhibition of apoptosis is a hallmark of cancer, induction of apoptosis in cancer cells is known to be an efficient strategy for the treatment of cancer. In the present study, the induction of apoptosis was investigated morphologically by AO/EB staining. The results revealed that LDM at low concentrations could induce the apoptosis of K562 cells. The most important factor in the mechanism of apoptosis is the activation of caspases. Caspases are proteases that participate in the control of cell growth and apoptosis (22). Caspase- 8 and caspase-9 are caspases upstream of the apoptosis signal transduction process, while caspase-3 is downstream, and all of these are effector molecules of cell apoptosis (23). The present study analyzed the protein expression level of caspase- 8 and caspase- 3 by western blot analysis. The results demonstrated that a low concentration of LDM could increase the expression of caspase- 8 and caspase-3 in K562 cells. Furthermore, the fact that LDM at a low concentration increased NBT reduction capacity indicated that it could induce the differentiation of K562 cells. Subsequently, morphological changes, including decreased nuclear to cytoplasm ratio following LDM treatment, were observed under a light microscope. The hemoglobin concentration in LDM-treated K562 cells was further evidenced by a colorimetry assay. Flow cytometric analysis revealed that LDM could increase the expression level of CD71 in K562 cells. These phenotypic changes are frequently taken as indications for cellular erythroid differentiation.

Malignant hematopoiesis is characterized by a lack of differentiation capacity. Cell differentiation is a process of gene selective expression. The presence of hemoglobin in a cell indicates that the cell gene is selectively expressed, indicating that the cell has differentiated. The effect of cell differentiation is often associated with the dysfunction of the transcription factors in the signal transduction pathway. GATAbinding factor 1 (GATA-1), NF-E2, T-cell acute lymphocytic leukemia protein 1 (TAL1) and Kruppel like factor 1 (KLF1) are major erythroid-specific transcription activators that bind to the $\beta$-globin locus and regulate transcription of the globin gene (24). GATA-1 is a major regulator of the expression of other erythroid-specific activators in human erythroid K562 cells. During red blood cell maturation, GATA-1 activates nearly all erythroid-specific genes, while silencing genes associated with the immature proliferative red blood cell precursor cells $(25,26)$. Hemoglobin is a specific protein. The presence of hemoglobin indicates that cells have differentiated into red blood cells. In order to investigate the mechanism of erythroid differentiation of LDM on K562 cells, the present study detected the hemoglobin contents and the GATA-1 protein expression in LDM-treated K562 cells. The results revealed that LDM at a low concentration could increase the hemoglobin contents and upregulate the GATA-1 protein expression in K562 cells.

In conclusion, a major finding of the present study was that low concentrations of lidamycin could upregulate and activate the caspase- 8 and caspase- 3 signaling pathway, which in turn may have contributed toward the induction of apoptosis and cancer cell growth inhibition. On the other hand, LDM at low concentrations upregulated the GATA-1 protein expression of K562 cells, which in turn may have contributed toward the induction of K562 cell erythroid differentiation. These results indicate that lidamycin may serve a positive role in challenging the differentiation-inducing therapy of chronic myelogenous leukemia.

\section{Acknowledgements}

Not applicable. 


\section{Funding}

The present study was supported by the National Science Foundation of Hebei Province (no. H2013209040) and the Chinese Academy of Medical Sciences (CAMS) Innovation Fund for Medical Sciences (no. 2017-I2M-1-010).

\section{Availability of data and materials}

The datasets used during the present study are available from the corresponding author upon reasonable request.

\section{Authors' contributions}

JC and JHG conceived and designed the study. CZ and LYG performed the experiments and prepared the manuscript. DM performed the image and data analysis. JC and JHG revised the manuscript. All authors read and approved the manuscript and agree to be accountable for all aspects of the research in ensuring that the accuracy or integrity of any part of the work are appropriately investigated and resolved.

\section{Ethics approval and consent to participate}

Not applicable.

\section{Patient consent for publication}

Not applicable.

\section{Competing interests}

The authors declare that they have no competing interests

\section{References}

1. Jabbour E and Kantarjian H: Chronic myeloid leukemia: 2014 update on diagnosis, monitoring, and management. Am J Hematol 89: 547-556, 2014.

2. Dickinson AM, Pearce KF, Norden J, O'Brien SG, Holler E, Bickeböller H, Balavarca Y, Rocha V, Kolb HJ, Hromadnikova I, et al: Impact of genomic risk factors on outcome after hematopoietic stem cell transplantation for patients with chronic myeloid leukemia. Haematologica 95: 922-927, 2010.

3. Rousselot P, Charbonnier A, Cony-Makhoul P, Agape P, Nicolini FE, Varet B, Gardembas M, Etienne G, Réa D, Roy L, et al: Loss of major molecular response as a trigger for restarting tyrosine kinase inhibitor therapy in patients with chronic-phase chronic myelogenous leukemia who have stopped imatinib after durable undetectable disease. J Clin Oncol 32: 424-430, 2014.

4. Song P, Ye L, Fan J, Li Y, Zeng X, Wang Z, Wang S, Zhang G, Yang P, Cao Z, et al: Asparaginase induces apoptosis and cytoprotective autophagy in chronic myeloid leukemia cells. Oncotarget 6 : 3861-3873, 2015.

5. Rahimi R, Mahdavi M, Pejman S, Zare P and Balalaei S: Inhibition of cell proliferation and induction of apoptosis in K562 human leukemia cells by the derivative (3-NpC) from dihydropyranochromenes family. Acta Biochim Pol 62: 83-88, 2015.

6. Marchwicka A, Cebrat M, Sampath P, Snieżewski L and Marcinkowska E: Perspectives of differentiation therapies of acute myeloid leukemia: The search for the molecular basis of patients' variable responses to 1,25-dihydroxyvitamin $\mathrm{d}$ and vitamin d analogs. Front Oncol 4: 125-137, 2014.
7. Takahashi H, Hatta Y, Iriyama N, Hasegawa Y, Uchida H, Nakagawa M, Makishima M, Takeuchi J and Takei M: Induced differentiation of human myeloid leukemia cells into M2 acrophages by combined treatment with retinoic acid and $1 \alpha, 25-$ dihydroxy vitamin D3. PLoS One 9: e113722, 2014.

8. Hu JL, Xue YC, Xie MY,Zhang R, Otani T, Minami Y, Yamada Y and Marunaka T: A new macromolecular antitumor antibiotic, C-1027. I. Discovery, taxonomy of producing organism, fermentation and biological activity. J Antibiot (Tokyo) 41: 1575-1579, 1988.

9. Sakata N, Ikeno S, Hori M, Hamada M and Otani T: Cloning and nucleotide sequencing of the antitumor antibiotic C-1027 apoprotein gene. Biosci Biotechnol Biochem 56: 1592-1595, 1992.

10. Tanaka T, Fukuda-Ishisaka S, Hirama M and Otani T: Solution structures of C-1027 apoprotein and its complex with the aromatized chromophore. J Mol Biol 309: 267-283, 2001.

11. Shao RG and Zhen YS: Relationship between the molecular composition of C1027, a new macromolecular antibiotic with enediyne chromophore, and its antitumor activity. Yao Xue Xue Bao 30: 336-342, 1995 (In Chinese).

12. Jiang W, Shang B, Li L, Zhang S and Zhen Y: Construction of a genetically engineered chimeric apoprotein consisting of sequences derived from lidamycin and neocarzinostatin. Anticancer Drugs 27: 24-28, 2016.

13. Dziegielewski J and Beerman TA: Cellular responses to the DNA strand-scission enediyne C-1027 can be independent of ATM, ATR, and DNA-PK kinases. J Biol Chem 277: 20549-20554, 2002.

14. Zhen YS, Ming XY, Yu B, Otani T, Saito H and Yamada Y: A new macromolecular antitumor antibiotic, C-1027. III. Antitumor activity. J Antibiot (Tokyo) 42: 1294-1298, 1989.

15. Xu YJ, Zhen YS and Goldberg IH: C1027 chromophore, a potent new enediyne antitumor antibiotic, induces sequence-specific double-strand DNA cleavage. Biochemistry 33: 5947-5954, 1994.

16. Zhen H, Xue Y and Zhen Y: Inhibition of angiogenesis by antitumor antibiotic C1027 and its effect on tumor metastasis. Zhonghua Yi Xue Za Zhi 77: 657-660, 1997 (In Chinese).

17. Huang YH, Shang BY and Zhen YS: Antitumor efficacy of lidamycin on hepatoma and active moiety of its molecule. World J Gastroenterol 11: 3980-3984, 2005.

18. Ding LL, Liu M, Zhang SH, Zhao XZ, Wu N, Chen L, Wang GJ and Lin XK: Lidamycin inhibits angiogenesis of zebrafish embryo via down-regulation of VEGF. Yao Xue Xue Bao 45: 456-461, 2010 (In Chinese).

19. Shao RG and Zhen YS: Enediyne anticancer antibiotic lidamycin: Chemistry, biology and pharmacology. Anticancer Agents Med Chem 8: 123-131, 2008.

20. Suzuki M, Tanaka H, Tanimura A, Tanabe K, Oe N, Rai S, Kon S, Fukumoto M, Takei K, Abe T, et al: The clathrin assembly protein PICALM is required for erythroid maturation and transferrin internalization in mice. PLoS One 7: e31854, 2012.

21. Xin C, Ye S, Ming Y, Shenghua Z, Qingfang M, Hongxing G, $\mathrm{Xu} \mathrm{S}$, Yuanfu X, Yuan Z, Dongmei F, et al: Efficient inhibition of B-cell lymphoma xenografts with a novel recombinant fusion protein: anti-CD20Fab-LDM. Gene Ther 17: 1234-1243, 2010.

22. Morgan CW, Julien O, Unger EK, Shah NM and Wells JA: Turning on caspases with genetics and small molecules. Methods Enzymol 544: 179-213, 2014.

23. Zhao Y, Lei M, Wang Z, Qiao $G$, Yang $T$ and Zhang $J$ : TCR-induced, PKC- $\theta$-mediated NF- $\kappa \mathrm{B}$ activation is regulated by a caspase- 8 -caspase- 9 -caspase- 3 cascade. Biochem Biophys Res Commun 450: 526-531, 2014.

24. Kang Y, Kim YW, Yun J, Shin J and Kim A: KLF1 stabilizes GATA-1 and TAL1 occupancy in the human $\beta$-globin locus. Biochim Biophys Acta 1849: 282-289, 2015.

25. Welch JJ, Watts JA, Vakoc CR, Yao Y, Wang H, Hardison RC, Blobel GA, Chodosh LA and Weiss MJ: Global regulation of erythroid gene expression by transcription factor GATA-1. Blood 104: 3136-3147, 2004.

26. Cheng Y, Wu W, Kumar SA, Yu D, Deng W, Tripic T, King DC, Chen KB, Zhang Y, Drautz D, et al: Erythroid GATA1 function revealed by genome-wide analysis of transcription factor occupancy, histone modifications, and mRNA expression. Genome Res 19: 2172-2184, 2009. 